\title{
Sleeping Time, BMI, and Body Fat in Chinese Freshmen and Their Interrelation
}

\author{
Yehong Yang ${ }^{a}$ Qing Miao ${ }^{a}$ b Xiaoming Zhu ${ }^{a} \quad$ Lang Qin $^{a} \quad$ Wei Gong $^{a}$ \\ Shuo Zhang ${ }^{a}$ Qiongyue Zhang ${ }^{a}, b \quad B i n L^{a}$ Hongying Ye ${ }^{a}$ Yiming Li $^{a}$ \\ a'Department of Endocrinology and Metabolism, Huashan Hospital, Fudan University, \\ Shanghai, China; ${ }^{b}$ Department of Endocrinology and Metabolism, Huashan Hospital North, \\ Fudan University, Shanghai, China
}

\section{Keywords}

BMI $\cdot$ Body fat $\cdot$ Sleep $\cdot$ Freshmen

\begin{abstract}
Introduction: In the past two decades, urbanization in many Asian countries has led to sedentary lifestyle and overnutrition, which has set the stage for the epidemic of obesity. Those who have obesity during adolescence usually have obesity into adulthood, which causes many medical and psychological issues that can result in premature death. Recent data suggest that short sleep duration may contribute to the risk of obesity, opening a new avenue for potential intervention. The aim of this study was to describe the prevalence of sleeping time, body mass index (BMI), and fat mass in Chinese freshmen and to indicate the relationship among them. Methods: We conducted a cross-sectional study consisting of 1,938 freshmen aged from 18 to 24 years, including 684 (35.3\%) men and 1,254 (64.7\%) women. BMI, sleeping time, and other potential related variables were collected by questionnaire. Obesity and overweight were defined as $\mathrm{BMI} \geq 28.0$ and $\geq 24.0$, respectively. All students were divided into three groups according to the tertiles of body fat percentage (Fat\%), which were measured by bioelectrical impedance analysis. Sleeping time was divided into 3 categories based on the duration, $<6$, $6-8$, and $>8$ h per day. Results: Participants who slept longer had lower BMI and Fat\%. Sex, diet control, and maternal obesity were all significantly associated with BMI or Fat\% after adjustment. There were significant differences between sleeping time $<6$ and $>8 \mathrm{~h}$ in both over-
\end{abstract}

Yehong Yang and Qing Miao contributed equally to this work. 
Yang et al.: Sleeping Time, BMI, and Body Fat in Chinese Freshmen and Their Interrelation

weight group and Fat\% tertiles independent of adjustment used. The significant difference between sleeping time $6-8$ and $>8 \mathrm{~h}$ only existed in overweight group, while irrelevant relation was observed in both models of obesity group. Conclusion: Longer sleeping time was associated with a lower BMI in Chinese freshmen, even after adjustment for multiple confounders. The overweight stage is a critical period of weight management intervention by changing sleeping time. If adolescents have entered the obesity stage, the effect size of lifestyle intervention might be significantly limited.

(C) 2020 The Author(s)

Published by S. Karger AG, Basel

\section{Introduction}

The prevalence and severity of obesity and overweight in different cohorts has been increasing worldwide and has more than doubled since 1980. In Asia, the prevalence of obesity was very low previously and recently is increasing at an alarming rate, especially in China, Japan, and India [1]. The number of Chinese obese people was below 0.1 million in 1975 and rose to 43.2 million in 2014, accounting for $16.3 \%$ of global obesity [2]. Adolescent obesity is an important predictor of obesity in adulthood. Compared to healthy weight youths, the risk of becoming obese in adulthood is approximately five times higher among boys and nine times higher among girls who are obese in youth [3].

It has long been known that obesity is associated with numerous comorbidities, including cardiovascular diseases, diabetes mellitus [4], musculoskeletal disorders [5], and several cancers [6]. Adults with obesity who also had obesity during adolescence have a higher risk of developing complications of obesity than those who become obese during adulthood but were normal weight during adolescence [7,8]. Furthermore, emerging evidence shows that childhood and adolescent obesity is positively related to weight gain in adults. Without intervention, these comorbidities, as well as obesity itself, usually continue into adulthood, which can result in premature death [8-11]. In addition, adults with obesity are likely to have children with obesity, thus passing all the problems of obesity on to the next generation [12-15]. As a result, obesity and overweight would cause expensive and difficult socioeconomic problems, which need continued effort to identify modifiable risk factors for them. Because the constellation of cardiometabolic risk factors is considered to be modifiable, the early identification of and intervention for adolescents with metabolic syndrome is an important contention for public health to improve their condition. Although genetic factors play an important role in the pathogenesis of obesity, human behavior and lifestyle, such as physical activity [16] and dietary habits [17], are also critical contributors to its clinical manifestation.

In parallel with the growing epidemics of obesity and overweight, sleeping time is decreasing in modern society. In the United States, data from the National Health Interview Survey (NHIS) has shown that self-reported mean sleeping time decreased by 10-15 min from 1985 to 2012, while the percentage of adults reporting less than $6 \mathrm{~h}$ of sleep per night increased from $22.3 \%$ to $29.2 \%$ [18]. Insufficient sleep may lead to negative social, psychological, and public health consequences, including motor vehicle accidents [19], poor functioning at school or work, and physical diseases [20]. Evidence from laboratory [21] and epidemiological studies [22] is accumulating to suggest the association between sleep deprivation and obesity [23]. On the other hand, investigators from the United States [24] have conducted cross-sectional studies together with prospective studies demonstrating an increased risk for overweight status or obesity in children, adolescents, and adults who have shorter sleep. As in the West, studies in Asian populations are on the rise simultaneously [25]. 
Yang et al.: Sleeping Time, BMI, and Body Fat in Chinese Freshmen and Their Interrelation

However, the relation between decreasing sleeping time and increasing obesity incidence is under debate. Some studies have reported U-shaped association [26], whereby both short and long sleeping time are associated with higher body mass index (BMI), while some others have found reverse association [27] in which shorter sleeping time is associated with greater BMI. Irrelevant association [28] has been documented as well. In the CARDIA and SWAN cohorts, two longitudinal studies that used actigraphy, no associations were found between short sleep duration and weight gain or incident obesity [29-31]. Sleeping time is differentially associated with BMI across population subgroups, such as sex or age. Some studies have found stronger associations among males, others have shown stronger effects among women or no sex difference [32]. Moreover, Hasler et al. [33] conducted a prospective study of adults showing that sleeping time was negatively associated with BMI in participants at age 27 years, but the association diminished after age 34 years. More work is needed to establish whether the short sleep-obesity association is causal.

China has experienced rapid socioeconomic growth over the past several decades, which has led to a transformation of lifestyle. The efficacy of lifestyle interventions to treat obesity has been proven for adolescents in randomized controlled trials and clinical studies, and lifestyle interventions are the recommended therapy for adolescents with obesity [34]. However, studies of sleep and BMI in China, especially in Chinese Mainland, are sparse. Few studies [35] have examined the association in a sample of youths, to our knowledge. College students are a special group, which is an important component of the overall health level of the society. This age group merits attention, as the transition to adulthood is associated with important changes in personal circumstances and behaviors that may impact both sleep and BMI. Therefore, it is important to study their sleep quality, as well as the relationship between sleep quality and body type. In addition, the government and school-related departments concerned should place great importance on the mental and physical health of college students $[36,37]$. Given the myriad factors that have been implicated in obesity in previous studies, adjustment for multiple confounders has not always been undertaken. While most studies have used BMI as primary outcome, there have been few studies assessing the change in body composition such as body fat percentage. Consequently, our group focused on the prevalence of sleeping time, BMI, and body fat percentage in Shanghai freshmen, tried to illustrate the relation among them, and tried to open some new avenues for potential intervention.

\section{Methods}

\section{Design and Sample}

This study was a cross-sectional survey of 18- to 24-year-olds in a multidisciplinary university, named Shanghai University of Finance and Economics, where students were recruited nationwide. All freshmen in this university were recruited during the first fall semester 2011. The aim of this study was to describe and analyze those college students' health behavior, weight status, fat percentage, and dieting practice. Trained investigators administered the questionnaire survey to 2000 students and measured relevant indicators. Sixty-two participants were excluded because of missing information or having abnormal medical examination including heart, liver, and kidney dysfunction and thyroid-stimulating hormone abnormalities, and 1,938 students (684 males and 1,254 females) participated in this baseline survey. Students recruited in this study came from 23 provinces, 4 municipalities of China including Han and minority. The study was approved by the institutional review board of Huashan Hospital, Fudan University. All participants agreed to provide their personal information regarding the purpose and the procedures of our study, and written informed consent was obtained. 
Yang et al.: Sleeping Time, BMI, and Body Fat in Chinese Freshmen and Their Interrelation

\section{Data Collection by Questionnaire}

We developed the questionnaire according to the Pittsburgh Sleep Quality Index (PSQI) [38] and the Three Factor Eating Questionnaire (TFEQ-18) [39]. Information on sociodemographic features, weight perception, dieting practices, disease history, family disease history, residential information, and a 2-year diet habit recall were collected through questionnaires.

\section{Medical and Anthropometric Examination}

Medical examination was performed by experienced doctors from Huashan Hospital. Anthropometric assessments were performed in the school's medical office by trained nurses from Huashan Hospital using standard methods. In brief, height was assessed to the nearest $0.1 \mathrm{~cm}$ using a precision stadiometer (SECA 225, Hamburg, Germany), and body weight was measured to the nearest $0.1 \mathrm{~kg}$ using a calibrated digital scale (SECA 861, Hamburg, Germany) with subjects wearing light underwear only and no shoes. The waist circumference was determined at the midline from the lower rib margin to the iliac crest to the nearest $0.1 \mathrm{~cm}$. BMI was calculated as weight $(\mathrm{kg}) /$ height squared $\left(\mathrm{m}^{2}\right)$. Obesity and overweight were defined as $\mathrm{BMI} \geq 28.0$ and $\geq 24.0$, respectively.

To fully grasp the scope of the obesity problem in Asia, one should understand that there are notable differences between the Asian and Western populations in terms of lifestyle, genetics, and body composition. In particular, Asians are more likely to have central fat deposition despite having a lower BMI [40]. This has led some to recommend different BMI cut-off points for the Asian population. Generally, obesity is conceptualized as maintaining a BMI higher than 30, whereas in China according to Zhou, it is proposed that the cutoff points for overweight and obesity were 24 and 28 , respectively.

\section{Body Fat Percentage}

A segmental bioelectrical impedance analysis scale (Tanita, type BC-418, Japan) was used to measure body fat percentage, fat mass, and fat-free mass. All students were divided into three groups according to the tertiles of the body fat percentage.

\section{Definition of Sleep Duration}

Appropriate and healthy sleep durations vary with age. Sleep duration tends to decrease with age during childhood and adolescence. The National Sleep Foundation (NSF) [41] and the American Academy of Sleep Medicine [42] recommend a healthy sleep duration based on age. For adolescents, very short sleep duration is defined as a sleep duration of $<6 \mathrm{~h}$, and the recommended sleeping time is defined as at least $8 \mathrm{~h}$ per $24-\mathrm{h}$ period. So, the sleeping time was divided into 3 categories based on the duration, $<6,6-8$, and $>8 \mathrm{~h}$ per day.

\section{Statistical Analyses}

All continuous variables were presented as the mean $\pm \mathrm{SD}$, absolute number, or percentages. The differences of general characteristics at baseline according to BMI classification were assessed by $t$ test or chi-square test. An unadjusted model and a multivariate model were used for the estimation of association between sleeping time and BMI. The factors with significant differences in univariate analysis were included in multivariate analysis. The multivariate model used in this study was adjusted for sex, diet control, maternal obesity, and sleeping time. Since the variance inflation factor is less than 10 , there is no multicollinearity among variables, which could be included in multivariate analysis. A $p$ value $<0.05$ was considered statistically significant. Statistical analysis was carried out using the SPSS version 24.0 . 
Yang et al.: Sleeping Time, BMI, and Body Fat in Chinese Freshmen and Their Interrelation

Table 1. Demographic characteristics of participants according to sex classification

\begin{tabular}{|c|c|c|c|c|c|}
\hline & \multicolumn{2}{|l|}{ Total } & \multicolumn{2}{|l|}{ Sex } & \multirow[t]{2}{*}{$p$} \\
\hline & $n$ & $\%$ & $\operatorname{men}(n=684)$ & women $(n=1,254)$ & \\
\hline Age, years ${ }^{\mathrm{a}}$ & \multicolumn{2}{|l|}{$20.4 \pm 0.8$} & $20.5 \pm 0.8$ & $20.3 \pm 0.7$ & $<0.01$ \\
\hline \multicolumn{6}{|l|}{ Ethnic Han, $n$} \\
\hline Han & 1,753 & $90.5 \%$ & $608(34.7 \%)$ & $1,144(65.3 \%)$ & \multirow[t]{2}{*}{0.113} \\
\hline Others & 177 & $9.1 \%$ & $72(40.7 \%)$ & $105(59.3 \%)$ & \\
\hline $\mathrm{BMI}^{\mathrm{a}}$ & $20.9 \pm 3.1$ & & $20.1 \pm 2.5$ & $22.1 \pm 3.5$ & $<0.01$ \\
\hline Normal & 1,672 & $86.3 \%$ & $18.1 \pm 0.9$ & $17.9 \pm 0.97$ & 0.259 \\
\hline Overweight & 200 & $10.3 \%$ & $20.3 \pm 0.6$ & $20.3 \pm 0.64$ & 0.599 \\
\hline Obesity & 64 & $3.3 \%$ & $24.8 \pm 2.9$ & $23.5 \pm 2.2$ & $<0.001$ \\
\hline Body fat percentage $^{a}$ & 20.9 & $5.9 \%$ & $17.6 \pm 5.7$ & $22.7 \pm 5.2$ & $<0.001$ \\
\hline \multicolumn{6}{|l|}{ Sleeping time } \\
\hline$<6 \mathrm{~h}$ & 103 & $5.3 \%$ & $32(31.1 \%)$ & $71(68.9 \%)$ & \multirow[t]{3}{*}{0.631} \\
\hline 6-8h & 1,513 & $78.1 \%$ & $539(36.3 \%)$ & $947(63.7 \%)$ & \\
\hline$>8 \mathrm{~h}$ & 312 & $16.1 \%$ & $108(7.9 \%)$ & $1,248(92.1 \%)$ & \\
\hline
\end{tabular}

${ }^{\text {a }}$ Data are shown as mean \pm SD.

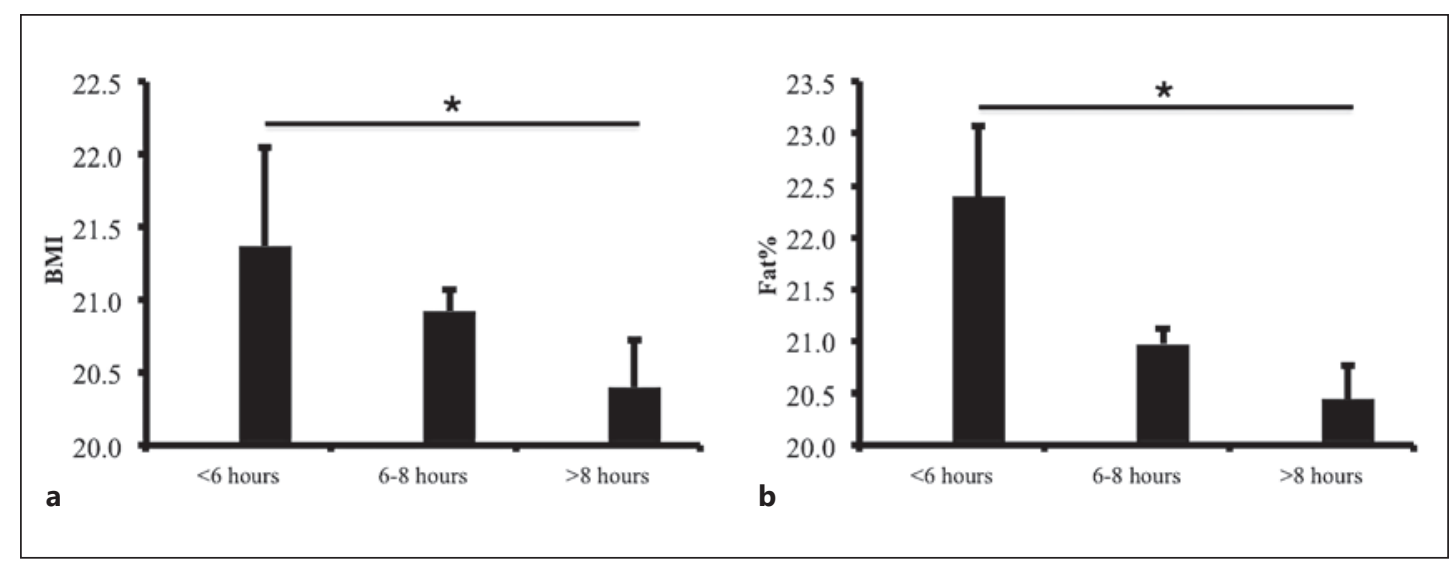

Fig. 1. Figures are means (SE) in sleeping time groups. a Relation between BMI and sleeping time. b Relation between body fat percentage (Fat\%) and sleeping time. * There was a significant difference between sleeping time $<6 \mathrm{~h}$ and $>8 \mathrm{~h}(p<0.05)$.

\section{Results}

1,938 participants (aged 20.4 \pm 0.8 , range 18-24) were recruited in this study, consisting of $35.3 \%$ men (aged $20.5 \pm 0.8$ ) and $64.7 \%$ women (aged $20.3 \pm 0.7$ ). $90.5 \%$ of the participants were ethnic Han with the others from minority. There was no significant difference in the distribution of ethnicity between different sexes. The mean BMI of the total sample was 20.9 \pm 3.1 (females vs. males: $22.1 \pm 3.5$ vs. $20.1 \pm 2.5, p<0.01$ ). The mean body fat percentage was $20.9 \pm 5.9 \%$ (females vs. males: $22.7 \pm 5.2$ vs. $17.6 \pm 5.7, p<0.001$ ). Most females preferred to sleep $>8 \mathrm{~h}$, while most males slept between 6 and 8 h. Table 1 shows demographic characteristics, anthropometric measures, and sleeping time across sexes.

As depicted in Figure 1, there was an inverse association between BMI, body fat percentage, and sleeping time categories. Participants sleeping $<6 \mathrm{~h}$ had the highest BMI $(21.4 \pm 3.5)$ compared to those who slept $>8 \mathrm{~h}$ possessing the lowest $(20.3 \pm 2.7)(p<0.05)$. Participants sleeping $6-8 \mathrm{~h}$ were in between $(20.9 \pm 5.9)$. Likewise, body fat percentage showed a similar 
Yang et al.: Sleeping Time, BMI, and Body Fat in Chinese Freshmen and Their Interrelation

Table 2. Unadjusted odds ratios and multivariate adjusted odds ratios for development of overweight (BMI $\geq 24$ vs. BMI <24)

\begin{tabular}{|c|c|c|c|c|}
\hline & \multicolumn{2}{|c|}{ Univariate model } & \multicolumn{2}{|c|}{ Multivariate model } \\
\hline & $p$ & OR (95\% CI) & $p$ & OR $(95 \% \mathrm{CI})$ \\
\hline Female (vs. male) & 0.000 & $0.213(0.161-0.281)$ & $<0.001$ & $0.164(0.122-0.221)$ \\
\hline Diet control & 0.000 & $0.458(0.343-0.610)$ & $<0.001$ & $0.331(0.242-0.452)$ \\
\hline Maternal obesity & 0.003 & $1.495(1.150-1.943)$ & $<0.001$ & $1.686(1.269-2.240)$ \\
\hline \multicolumn{5}{|l|}{ Sleeping time } \\
\hline$<6 \mathrm{~h}$ & 0.023 & $2.091(1.106-3.952)$ & 0.006 & $2.605(1.307-5.191)$ \\
\hline 6-8h & 0.020 & $1.626(1.081-2.447)$ & 0.018 & $1.688(1.092-2.608)$ \\
\hline$>8 \mathrm{~h}$ & ref & ref & ref & ref \\
\hline Age & 0.170 & $1.127(0.095-1.337)$ & & \\
\hline Ethnicity & 0.477 & $0.855(0.555-1.317)$ & & \\
\hline Medical history & 0.771 & $0.938(0.612-1.438)$ & & \\
\hline Breakfast free & 0.495 & $1.308(0.605-2.832)$ & & \\
\hline Vegetables intake & 0.718 & $1.073(0.733-1.569)$ & & \\
\hline
\end{tabular}

ref, reference; OR, odds ratio; $\mathrm{CI}$, confidence interval.

Table 3. Unadjusted odds ratios and multivariate adjusted odds ratios for development of obesity (BMI $\geq 28$ vs. BMI <28)

\begin{tabular}{|c|c|c|c|c|}
\hline & \multicolumn{2}{|c|}{ Univariate model } & \multicolumn{2}{|c|}{ Multivariate model } \\
\hline & $p$ & OR $(95 \% \mathrm{CI})$ & $p$ & OR $(95 \% \mathrm{CI})$ \\
\hline Female (vs. male) & $<0.001$ & $0.175(0.098-0.310)$ & $<0.001$ & $0.149(0.083-0.268)$ \\
\hline Diet control & 0.003 & $0.410(0.228-0.738)$ & $<0.001$ & $0.322(0.177-0.585)$ \\
\hline Maternal obesity & 0.361 & $1.259(0.768-2.066)$ & 0.247 & $1.353(0.811-2.258)$ \\
\hline \multicolumn{5}{|l|}{ Sleeping time } \\
\hline$<6 \mathrm{~h}$ & 0.401 & $1.861(0.437-7.925)$ & 0.275 & $2.270(0.521-9.894)$ \\
\hline $6-8 \mathrm{~h}$ & 0.077 & $2.302(0.914-5.798)$ & 0.082 & $2.289(0.900-5.825)$ \\
\hline$>8 \mathrm{~h}$ & ref & ref & ref & ref \\
\hline Age & 0.822 & $0.999(0.987-1.010)$ & & \\
\hline Ethnicity & 0.646 & $0.873(0.490-1.556)$ & & \\
\hline Medical history & 0.391 & $1.886(0.442-8.051)$ & & \\
\hline Breakfast free & 0.099 & $0.869(0.736-1.027)$ & & \\
\hline Vegetables intake & 0.718 & $0.929(0.625-1.382)$ & & \\
\hline
\end{tabular}

ref, reference; OR, odds ratio; $\mathrm{CI}$, confidence interval.

trend along with sleeping time. Body fat percentage of participants sleeping $<6,6-8$, and $>8 \mathrm{~h}$ were $22.4 \pm 6.8,21.0 \pm 5.8$, and $20.4 \pm 5.7$, respectively. There was a significant difference between sleeping time $<6 \mathrm{~h}$ and $>8 \mathrm{~h}(p<0.05)$.

Table 2 and 3 present the association between BMI and related factors for both univariate and multivariate models. Table 2 is based on overweight (BMI 24) and Table 3 is based on obesity (BMI 28). In the univariate analyses of Table 2, sex, diet control, and maternal obesity were all significantly associated with BMI $(p<0.01)$; sleeping time had inverse relation as well $(p<0.05)$. Females were approximately a quintile less likely to be overweight compared to males (odds ratio [OR] $=0.213,95 \% \mathrm{CI}$ : $0.161-0.281$ ). The corresponding ORs for diet control and maternal obesity were OR $=0.458$ (95\% CI: 0.343-0.610) and OR $=1.495(95 \%$ CI: 1.150-1.943), respectively. Using the participants sleeping $>8 \mathrm{~h}$ as a reference, the ORs for those sleeping <6 and 6-8 h were 2.091 (95\% CI: 1.106-3.952) and 1.626 (95\% CI: $1.081-$ 
Yang et al.: Sleeping Time, BMI, and Body Fat in Chinese Freshmen and Their Interrelation

Table 4. Unadjusted odds ratios and multivariate adjusted odds ratios for body fat percentage tertile 3 versus tertiles 1 and 2

\begin{tabular}{|c|c|c|c|c|}
\hline & \multicolumn{2}{|c|}{ Univariate model } & \multicolumn{2}{|c|}{ Multivariate model } \\
\hline & $p$ & OR $(95 \% \mathrm{CI})$ & $p$ & OR $(95 \% \mathrm{CI})$ \\
\hline Female (vs. male) & 0.000 & 3.687 (2.929-4.642) & $<0.001$ & $3.258(2.561-4.145)$ \\
\hline Diet control & 0.000 & $0.385(0.313-0.473)$ & $<0.001$ & $0.423(0.340-0.526)$ \\
\hline Maternal obesity & 0.001 & $1.359(1.125-1.641)$ & 0.001 & $1.387(1.134-1.697)$ \\
\hline \multicolumn{5}{|l|}{ Sleeping time } \\
\hline$<6 \mathrm{~h}$ & 0.016 & $1.754(1.111-2.768)$ & 0.011 & $1.899(1.159-3.111)$ \\
\hline $6-8 \mathrm{~h}$ & 0.554 & $1.082(0.833-1.407)$ & 0.471 & $1.110(0.835-1.476)$ \\
\hline$>8 \mathrm{~h}$ & ref & ref & ref & ref \\
\hline Age & 0.277 & $0.932(0.820-1.058)$ & & \\
\hline Ethnicity & 0.299 & $1.196(0.854-1.674)$ & & \\
\hline Medical history & 0.530 & $0.905(0.664-1.235)$ & & \\
\hline Breakfast free & 0.616 & $1.168(0.637-2.141)$ & & \\
\hline Vegetables intake & 0.443 & $1.115(0.844-1.303)$ & & \\
\hline
\end{tabular}

ref, reference; OR, odds ratio; CI, confidence interval.

2.447), respectively. After adjustment for the known covariates in multivariate model, there were substantial changes of $p$ values and ORs in the estimate of sex, diet control, maternal obesity, and sleeping time. The corresponding ORs for sex, diet control, and maternal obesity became OR $=0.164$ (95\% CI: $0.122-0.221), \mathrm{OR}=0.331$ (95\% CI: $0.242-0.452$ ), and OR $=1.686$ (95\% CI: 1.269-2.240), respectively. The $p$ value of sleeping time $<6$ h changed to $<0.01$, while the corresponding ORs for sleeping time $<6$ and $6-8 \mathrm{~h}$ changed to OR $=2.605$ (95\% CI: $1.307-$ 5.191 ) and $\mathrm{OR}=1.688$ (95\% CI: 1.092-2.608). In the univariate and multivariate model of Table 3, sex and diet control were still significantly associated with BMI $(p<0.01)$, but maternal obesity and sleeping time were no longer statistically significant. As detailed in Table 4, variables of sex, diet control, and maternal obesity were observed to have similar relation with body fat percentage independent of the adjustment used $(p<0.01)$. There was a significant difference between sleeping time $<6$ and $>8 \mathrm{~h}$ both in the univariate model and the multivariate model $(p<0.05)$, but no significant difference was found between sleeping time $6-8$ and $>8 \mathrm{~h}$ in the two models.

\section{Discussion}

The prevalence of overweight and obesity has reached epidemic proportions in Western nations and has been increasing in developing nations as well. The growing rates of obesity have important health consequences, including increasing the risk of a host of diseases including degenerative joint disease, type 2 diabetes, cardiovascular disease, and obesityassociated malignancies. Obesity in children and adolescent appears to be predominantly a problem of the rich in low- and middle-income countries.

Body weight is influenced by an interaction of factors including dietary behaviors, physical activity, sedentary behaviors, and genetic predisposition, among others. These determinants are themselves affected by complex multilevel interacting determinants at the individual, interpersonal, and societal levels [43]. As economic transition advances, it is predicted that the current mean BMI trends depicted in developing nations will surpass even the maximum mean BMI values reported in developed countries. Such an increase in over- 
Yang et al.: Sleeping Time, BMI, and Body Fat in Chinese Freshmen and Their Interrelation

weight can be attributed to significant alterations in eating habits and physical activity level caused by socioeconomic influences [44]. The literature documents socioeconomic gradients in dietary behaviors $[45,46]$ and sedentary behaviors $[47,48]$, with youths from a low socioeconomic background generally displaying more unfavorable behaviors. Besides this, recent data suggests that poor sleep habits may contribute to the risk of obesity, opening a new avenue for potential intervention [49]. In this paper, we describe the characteristics of sleeping time, BMI, and fat mass in Chinese freshmen and indicate the relationship among them.

Freshmen recruited in the current survey comprise a variety of multiethnic and socioeconomically diverse samples. As in our study, it seems that Chinese freshmen have a thinner body shape with mean BMI $20.9 \pm 3.1$ and body fat percentage $20.9 \pm 5.9 \%$ compared to their corresponding partners [33]. Most of freshmen sleep for a moderate amount of time, 6-8 h, in accordance with previous studies [25], while the least sleep $<6 \mathrm{~h}$. Females seem more likely to be obese than males. Similarly, females tend to contain higher body fat percentage. There is no significant difference in sleeping time across sexes.

The present results are generally consistent with inverse association between sleeping time and BMI, body fat percentage across different categories regarding populations of youths [27], which does not corroborate a U-shaped association as shown in several previous studies [26]. The significant differences of confounders including sex, diet control, and maternal obesity in BMI and body fat percentage persist despite of the adjustment used. It should be noted that the association between BMI, body fat percentage, and sleeping time. The differences between sleeping time $<6$ and $>8 \mathrm{~h}$ are significant in both BMI categories based on overweight and body fat percentage categories, independent of the adjustment used. The significant difference between sleeping time 6-8 and $>8 \mathrm{~h}$ only exists in BMI categories based on overweight in the univariate and multivariate analyses. Irrelevant relation between either $<6$ and $>8 \mathrm{~h}$ or $6-8$ and $>8 \mathrm{~h}$ are observed in BMI categories based on obesity. This suggests that the overweight stage is a critical period of weight management intervention by changing sleeping time. If adolescents have entered the obesity stage, the effect size of lifestyle intervention might be significantly reduced.

The mechanisms underlying the relationship between sleeping and obesity or BMI remain incompletely understood. Proposed mechanisms explaining the shortened sleep associated with higher BMI and body fat percentage include (i) added time awake provides more opportunity to eat; (ii) increased hunger from hormones signaling appetite and reduced satiety from hormones promoting satiation; (iii) altered thermoregulation; and (iv) increased fatigue, implying lower physical activity level [50-53]. Experiments have suggested that sleep curtailment seems to increase sympathetic nervous system activity. Meanwhile, various changes of hormones have resulted from insufficient sleep, such as increased evening cortisol, growth hormone and ghrelin level, reduced thyroid-stimulating hormone and leptin [54]. Accumulating evidence has indicated that sleep curtailment could also promote cytokine secretion in the adipose tissue and systemically, like increasing C-reactive protein, IL-6, and TNF- $\alpha$ [55]. Not only physical changes may increase appetite especially for energy-rich food like snacks [56], but also sleep deprivation itself may offer more opportunities to eat [57]. Another plausible explanation is that individuals who get insufficient sleep are more likely to experience fatigue, which could make them prefer to engage in sedentary behaviors rather than physical activity [57].

The strengths of our study include a large sample size, the use of well-trained interviewers, and the valuable data pool. This study is a cluster sampling study from the real-world evidence. We collected data of all freshmen in this multidisciplinary university and described the characteristics of BMI, body fat percentage, and sleeping time. Although the present study was conducted in Shanghai alone, it incorporated 23 provinces, 4 municipalities of China 
Yang et al.: Sleeping Time, BMI, and Body Fat in Chinese Freshmen and Their Interrelation

including Han and minority, which could be crudely representative of the national data. Moreover, the body composition was considered in the present survey, which made up for the limitation of BMI as the only assessment of body weight state. Adjustment for multiple confounders mitigates the potential effects on statistics of variables. Our results support the conclusion that sleeping time is associated with BMI and body composition in Asian young adults.

However, there are several limitations in our study as well. First, use of self-reports of sleeping time may lead to systematic bias as previous studies have shown that sleeping time by self-reports seems longer than objective measurements. However, it has been shown that there is reasonably close agreement between self-reports and objective measurements of sleeping time [58]. Secondly, BMI and body fat percentage are not representative of whole sex differences; it is not clear whether we would have observed other measures, such as waist circumference. Thirdly, not all essential parameters are included in our study, such as physical activity, sedentary behavior [16], and depression as such. Last but not least, cross-sectional research is capable of discovering the possible association between multiple variables but cannot validate their interrelation. Most of the literature has paid attention to the effects of sleep on obesity [24, 25], but the reverse directionality is also a possible scenario, which requires more prospective longitudinal and intervention studies to provide clearer insights into causality.

In conclusion, the medical, financial, and social consequences of the emerging epidemic of obesity in adolescents are substantial and demand an urgent response from health professionals and policymakers. Prevention in high-risk groups seems to be a promising strategy in addition to changing the obesogenic environment to create an environment in which healthy behavior is not only possible but also rewarded [59]. Although sex and maternal obesity have important effects on overweight and obesity in adolescents, these factors cannot be clinically intervened, so diet control and sleep intervention are more significant to clinicians. To our best knowledge, it is the first study to investigate the characteristics of BMI and body fat percentage and their relationship with sleeping time in Chinese Mainland freshmen. Sleep seems to be an important factor of body weight status in freshmen even after controlling for multiple confounders. Therefore, appropriate sleep habits should be encouraged to benefit public health. Whether improvement of sleep habits is capable of impacting favorably on body weight and other health outcomes remains to be seen.

\section{Acknowledgement}

We would like to thank all the students who participated in this study.

\section{Statement of Ethics}

Ethical approval was obtained from the local ethics committee at Huashan Hospital, Fudan University.

\section{Disclosure Statement}

The authors have no conflicts of interest to declare. 
Yang et al.: Sleeping Time, BMI, and Body Fat in Chinese Freshmen and Their Interrelation

\section{Funding Sources}

We acknowledge financial support from the National Natural Science Foundation of China (81800691, 81471083, 81670751, 81000329), National Key R\&D Program of China (2016YFC1305105), Shanghai Municipal Commission of Health and Family Planning (No. 20164Y0041, 20144Y0070, ZHYY-ZXYJHZX-1-01), Scientific Research Project supported by Huashan Hospital, Fudan University (No. 2013QD10).

\section{Author Contributions}

Y.Y. and Q.M. conceived, designed, and did statistical analysis and editing of manuscript; X.Z., L.Q., W.G., S.Z., Q.Z., B.L., and H.Y. did data collection and manuscript writing; Y.L. did review and final approval of manuscript.

\section{References}

1 Chakraborty C, Das S. Dynamics of Diabetes and Obesity: An Alarming Situation in the Developing Countries in Asia. Mini Rev Med Chem. 2016;16(15):1258-68.

2 Fan JG, Kim SU, Wong VW. New trends on obesity and NAFLD in Asia. J Hepatol. 2017 Oct;67(4):862-73.

3 Venn AJ, Thomson RJ, Schmidt MD, Cleland VJ, Curry BA, Gennat HC, et al. Overweight and obesity from childhood to adulthood: a follow-up of participants in the 1985 Australian Schools Health and Fitness Survey. Med J Aust. 2007 May;186(9):458-60.

4 Lee JM, Pilli S, Gebremariam A, Keirns CC, Davis MM, Vijan S, et al. Getting heavier, younger: trajectories of obesity over the life course. Int J Obes. 2010 Apr;34(4):614-23.

5 Thijssen E, van Caam A, van der Kraan PM. Obesity and osteoarthritis, more than just wear and tear: pivotal roles for inflamed adipose tissue and dyslipidaemia in obesity-induced osteoarthritis. Rheumatology (Oxford). 2015 Apr;54(4):588-600.

6 Keum N, Greenwood DC, Lee DH, Kim R, Aune D, Ju W, et al. Adult weight gain and adiposity-related cancers: a dose-response meta-analysis of prospective observational studies. J Natl Cancer Inst. 2015 Mar; 107(2):djv088.

7 Afshin A, Forouzanfar MH, Reitsma MB, Sur P, Estep K, Lee A, et al.; GBD 2015 Obesity Collaborators. Health Effects of Overweight and Obesity in 195 Countries over 25 Years. N Engl J Med. 2017 Jul;377(1):13-27.

8 Twig G, Yaniv G, Levine H, Leiba A, Goldberger N, Derazne E, et al. Body-Mass Index in 2.3 Million Adolescents and Cardiovascular Death in Adulthood. N Engl J Med. 2016 Jun;374(25):2430-40.

9 Whitaker RC, Wright JA, Pepe MS, Seidel KD, Dietz WH. Predicting obesity in young adulthood from childhood and parental obesity. N Engl J Med. 1997 Sep;337(13):869-73.

10 Baker JL, Olsen LW, Sørensen TI. Childhood body-mass index and the risk of coronary heart disease in adulthood. N Engl J Med. 2007 Dec;357(23):2329-37.

11 Biro FM, Wien M. Childhood obesity and adult morbidities. Am J Clin Nutr. 2010 May; 91(5):1499S-505S.

12 Carolan-Olah M, Duarte-Gardea M, Lechuga J. A critical review: early life nutrition and prenatal programming for adult disease. J Clin Nurs. 2015 Dec;24(23-24):3716-29.

13 Chang L, Neu J. Early factors leading to later obesity: interactions of the microbiome, epigenome, and nutrition. Curr Probl Pediatr Adolesc Health Care. 2015 May;45(5):134-42.

14 Katzmarzyk PT, Barlow S, Bouchard C, Catalano PM, Hsia DS, Inge TH, et al. An evolving scientific basis for the prevention and treatment of pediatric obesity. Int J Obes. 2014 Jul;38(7):887-905.

15 Roth CL, Sathyanarayana S. Mechanisms affecting neuroendocrine and epigenetic regulation of body weight and onset of puberty: potential implications in the child born small for gestational age (SGA). Rev Endocr Metab Disord. 2012 Jun;13(2):129-40.

16 Must A, Tybor DJ. Physical activity and sedentary behavior: a review of longitudinal studies of weight and adiposity in youth. Int J Obes. 2005 Sep;29(S2 Suppl 2):S84-96.

17 Vadiveloo M, Dixon LB, Mijanovich T, Elbel B, Parekh N. Dietary variety is inversely associated with body adiposity among US adults using a novel food diversity index. J Nutr. 2015 Mar;145(3):555-63.

18 Ford ES, Cunningham TJ, Croft JB. Trends in Self-Reported Sleep Duration among US Adults from 1985 to 2012. Sleep (Basel). 2015 May;38(5):829-32.

19 Pack AI, Maislin G, Staley B, Pack FM, Rogers WC, George CF, et al. Impaired performance in commercial drivers: role of sleep apnea and short sleep duration. Am J Respir Crit Care Med. 2006 Aug;174(4):446-54.

20 Gottlieb DJ, Redline S, Nieto FJ, Baldwin CM, Newman AB, Resnick HE, et al. Association of usual sleep duration with hypertension: the Sleep Heart Health Study. Sleep. 2006 Aug;29(8):1009-14. 
Yang et al.: Sleeping Time, BMI, and Body Fat in Chinese Freshmen and Their Interrelation

21 Taheri S, Lin L, Austin D, Young T, Mignot E. Short sleep duration is associated with reduced leptin, elevated ghrelin, and increased body mass index. PLoS Med. 2004 Dec;1(3):e62.

22 Marshall NS, Glozier N, Grunstein RR. Is sleep duration related to obesity? A critical review of the epidemiological evidence. Sleep Med Rev. 2008 Aug;12(4):289-98.

23 Ford ES, Li C, Wheaton AG, Chapman DP, Perry GS, Croft JB. Sleep duration and body mass index and waist circumference among U.S. adults. Obesity (Silver Spring). 2014 Feb;22(2):598-607.

24 Garaulet M, Ortega FB, Ruiz JR, Rey-López JP, Béghin L, Manios Y, et al. Short sleep duration is associated with increased obesity markers in European adolescents: effect of physical activity and dietary habits. The HELENA study. Int J Obes. 2011 Oct;35(10):1308-17.

25 Kong AP, Wing YK, Choi KC, Li AM, Ko GT, Ma RC, et al. Associations of sleep duration with obesity and serum lipid profile in children and adolescents. Sleep Med. 2011 Aug;12(7):659-65.

26 Chaput JP, Després JP, Bouchard C, Tremblay A. Short sleep duration is associated with reduced leptin levels and increased adiposity: results from the Quebec family study. Obesity (Silver Spring). 2007 Jan;15(1):25361.

27 Arora T, Jiang CQ, Thomas GN, Lam KB, Zhang WS, Cheng KK, et al. Self-reported long total sleep duration is associated with metabolic syndrome: the Guangzhou Biobank Cohort Study. Diabetes Care. 2011 Oct;34(10): 2317-9.

28 Calamaro CJ, Park S, Mason TB, Marcus CL, Weaver TE, Pack A, et al. Shortened sleep duration does not predict obesity in adolescents. J Sleep Res. 2010 Dec;19(4):559-66.

29 Lauderdale DS, Knutson KL, Rathouz PJ, Yan LL, Hulley SB, Liu K. Cross-sectional and longitudinal associations between objectively measured sleep duration and body mass index: the CARDIA Sleep Study. Am J Epidemiol. 2009 Oct;170(7):805-13.

30 Appelhans BM, Janssen I, Cursio JF, Matthews KA, Hall M, Gold EB, et al. Sleep duration and weight change in midlife women: the SWAN sleep study. Obesity (Silver Spring). 2013 Jan;21(1):77-84.

31 Vgontzas AN, Fernandez-Mendoza J, Miksiewicz T, Kritikou I, Shaffer ML, Liao D, et al. Unveiling the longitudinal association between short sleep duration and the incidence of obesity: the Penn State Cohort. Int J Obes. 2014 Jun;38(6):825-32.

32 Suglia SF, Kara S, Robinson WR. Sleep duration and obesity among adolescents transitioning to adulthood: do results differ by sex? J Pediatr. 2014 Oct;165(4):750-4.

33 Hasler G, Buysse DJ, Klaghofer R, Gamma A, Ajdacic V, Eich D, et al. The association between short sleep duration and obesity in young adults: a 13-year prospective study. Sleep. 2004 Jun 15;27(4):661-6.

34 O'Connor EA, Evans CV, Burda BU, Walsh ES, Eder M, Lozano P. Screening for Obesity and Intervention for Weight Management in Children and Adolescents: Evidence Report and Systematic Review for the US Preventive Services Task Force. JAMA. 2017 Jun;317(23):2427-44.

35 Spiegel K, Tasali E, Penev P, Van Cauter E. Brief communication: sleep curtailment in healthy young men is associated with decreased leptin levels, elevated ghrelin levels, and increased hunger and appetite. Ann Intern Med. 2004 Dec;141(11):846-50.

36 Xiang YT, Ma X, Lu JY, Cai ZJ, Li SR, Xiang YQ, et al. Relationships of sleep duration with sleep disturbances, basic socio-demographic factors, and BMI in Chinese people. Sleep Med. 2009 Dec;10(10):1085-9.

37 Tu X, Cai H, Gao YT, Wu X, Ji BT, Yang G, et al. Sleep duration and its correlates in middle-aged and elderly Chinese women: the Shanghai Women's Health Study. Sleep Med. 2012 Oct;13(9):1138-45.

38 Buysse DJ, Reynolds CF 3rd, Monk TH, Berman SR, Kupfer DJ. The Pittsburgh Sleep Quality Index: a new instrument for psychiatric practice and research. Psychiatry Res. 1989 May;28(2):193-213.

39 de Lauzon B, Romon M, Deschamps V, Lafay L, Borys JM, Karlsson J, et al.; Fleurbaix Laventie Ville Sante Study Group. The Three-Factor Eating Questionnaire-R18 is able to distinguish among different eating patterns in a general population. J Nutr. 2004 Sep;134(9):2372-80.

40 Chan JC, Malik V, Jia W, Kadowaki T, Yajnik CS, Yoon KH, et al. Diabetes in Asia: epidemiology, risk factors, and pathophysiology. JAMA. 2009 May;301(20):2129-40.

41 Hirshkowitz M, Whiton K, Albert SM, Alessi C, Bruni O, DonCarlos L, et al. National Sleep Foundation's sleep time duration recommendations: methodology and results summary. Sleep Health. 2015 Mar;1(1): 40-3.

42 Paruthi S, Brooks LJ, D’Ambrosio C, Hall WA, Kotagal S, Lloyd RM, et al. Recommended Amount of Sleep for Pediatric Populations: A Consensus Statement of the American Academy of Sleep Medicine. J Clin Sleep Med. 2016 Jun;12(6):785-6.

43 Ulijaszek SJ, Pentecost M, Marcus C, Karpe F, Frühbeck G, Nowicka P. Inequality and childhood overweight and obesity: a commentary. Pediatr Obes. 2017 Jun;12(3):195-202.

44 Bhurosy T, Jeewon R. Overweight and obesity epidemic in developing countries: a problem with diet, physical activity, or socioeconomic status? ScientificWorldJournal. 2014;2014:964236.

45 van der Horst K, Oenema A, Ferreira I, Wendel-Vos W, Giskes K, van Lenthe F, et al. A systematic review of environmental correlates of obesity-related dietary behaviors in youth. Health Educ Res. 2007 Apr;22(2): 203-26.

46 Pearson N, Biddle SJ, Gorely T. Family correlates of fruit and vegetable consumption in children and adolescents: a systematic review. Public Health Nutr. 2009 Feb;12(2):267-83.

47 Salmon J, Tremblay MS, Marshall SJ, Hume C. Health risks, correlates, and interventions to reduce sedentary behavior in young people. Am J Prev Med. 2011 Aug;41(2):197-206. 
Yang et al.: Sleeping Time, BMI, and Body Fat in Chinese Freshmen and Their Interrelation

48 Gebremariam MK, Altenburg TM, Lakerveld J, Andersen LF, Stronks K, Chinapaw MJ, et al. Associations between socioeconomic position and correlates of sedentary behaviour among youth: a systematic review. Obes Rev. 2015 Nov;16(11):988-1000.

49 Ogilvie RP, Patel SR. The epidemiology of sleep and obesity. Sleep Health. 2017 Oct;3(5):383-8.

50 Patel SR, Hu FB. Short sleep duration and weight gain: a systematic review. Obesity (Silver Spring). 2008 Mar; 16(3):643-53.

51 Chaput JP, Després JP, Bouchard C, Tremblay A. The association between short sleep duration and weight gain is dependent on disinhibited eating behavior in adults. Sleep (Basel). 2011 0ct;34(10):1291-7.

52 van Strien T, Koenders PG. Effects of emotional eating and short sleep duration on weight gain in female employees. J Occup Environ Med. 2014 Jun;56(6):659-66.

53 Ash T, Taveras EM. Associations of short sleep duration with childhood obesity and weight gain: summary of a presentation to the National Academy of Science's Roundtable on Obesity Solutions. Sleep Health. 2017 Oct; 3(5):389-92.

54 Van Cauter E, Spiegel K, Tasali E, Leproult R. Metabolic consequences of sleep and sleep loss. Sleep Med. 2008 Sep;9 Suppl 1:S23-8.

55 Patel SR, Zhu X, Storfer-Isser A, Mehra R, Jenny NS, Tracy R, et al. Sleep duration and biomarkers of inflammation. Sleep. 2009 Feb;32(2):200-4.

56 Nedeltcheva AV, Kilkus JM, Imperial J, Kasza K, Schoeller DA, Penev PD. Sleep curtailment is accompanied by increased intake of calories from snacks. Am J Clin Nutr. 2009 Jan;89(1):126-33.

57 Patel SR. Reduced sleep as an obesity risk factor. Obes Rev. 2009 Nov; 10 Suppl 2:61-8.

58 Knutson KL, Lauderdale DS. Sleep duration and overweight in adolescents: self-reported sleep hours versus time diaries. Pediatrics. 2007 May;119(5):e1056-62.

59 Reinehr T. Long-term effects of adolescent obesity: time to act. Nat Rev Endocrinol. 2018 Mar;14(3):183-8. 